\title{
Metabolic Impact of the Amount and Type of Dietary Carbohydrates on the Risk of Obesity and Diabetes
}

\author{
Begoña Manuel-y-Keenoy*,1 and Lucía Perez-Gallardo² \\ ${ }^{1}$ Laboratory of Nutrition and Functional Food Science, Faculty of Pharmacy, Biomedical \& Veterinary Sciences, \\ University of Antwerp, Belgium \\ ${ }^{2}$ Department of Biochemistry, University of Valladolid, Spain
}

\begin{abstract}
The relationship between dietary carbohydrates and the current obesity and diabetes epidemic is the subject of intense renewed interest. Since glucose is an essential source of energy, with limited body stores, maintenance of blood levels and changes in its metabolism are strongly determined by the intake of carbohydrates in the diet. Depending on the individual genetic susceptibility and the impact of other risk factors, these metabolic changes can potentially deteriorate into manifest abnormalities with an important disease risk.

In this review we focus on the impact of changing the quantity and quality of dietary carbohydrates on the biochemistry of fat synthesis and storage and on the metabolic abnormalities that can lead to overweight and obesity and to complications such as the metabolic syndrome and type 2 diabetes mellitus.

Using simple illustrations of the metabolic pathways involved, we summarize current research on the following issues:

- Does an increase in dietary carbohydrates induce changes in blood lipids and an increase in body fat?

- Does a diet with a high glycemic index lead to higher energy intakes, obesity and a higher risk of developing type 2 diabetes mellitus?

- Is sucrose more obesigenic than starch?

- Does excessive consumption of food and drinks sweetened with fructose explain the current epidemic of obesity and diabetes?

Despite convincing experimental data explaining the metabolic outcomes of excess consumption of these carbohydrate types, the evidence from dietary intervention studies has been undermined by methodological issues. Clear nomenclature and classification are still needed before this information can be applied to explain metabolic risks in each individual as well as to set up guidelines for the public health authorities and the food industry.
\end{abstract}

Keywords: Obesity, diabetes mellitus, sucrose, glycemic index, fructose, lipogenesis.

\section{INTRODUCTION}

\section{The Obesity Epidemic and Carbohydrates}

The current obesity epidemic is becoming a major public health burden both in developed and developing countries. More than ten years ago the World Health Organization estimated that $90 \%$ of diabetes mellitus type 2 and $30-40 \%$ of cardiovascular disease cases are directly caused by obesity [1]. It also predicts that by 20151,5 billion people will be overweight and that 2,6 million people will die every year as a result of being overweight or obese [2].

Even small changes in body weight $(5 \mathrm{~kg})$ have an impact on health. In particular, an excess of abdominal (rather than peripheral) fat, as seen, for example, with increases of 5 $\mathrm{cm}$ in waist circumference, is associated with increased

*Address correspondence to this author at the Laboratory of Nutrition and Functional Food Science, Faculty of Pharmacy, Biomedical and Veterinary Sciences, University of Antwerp campus Drie Eiken, A 1.30, Universiteitsplein 1, B-2610 Wilrijk-Antwerp, Belgium; Tel: +32(0)3 2652732; Fax:+32(0)32632734; E-mail: begona.manuelykeenoy@ua.ac.be disease risk [3]. These changes are always the inevitable result of an imbalance between energy intake and expenditure. This imbalance reflects a shift in life habits favoring a diet with a caloric content that is excessive for the often low levels of physical activity [4, 5].

In this review we discuss the potential obesigenic effects of increasing the quantity of carbohydrates both in absolute terms as well as relative to the fat intake. In the second part, we analyze the impact of the type of carbohydrate and summarize the changes induced by added sugars, rapidly digestible and high glycemic index carbohydrates and fructose.

Since 40 to $70 \%$ of the phenotypic variability of obesity is determined by more than 200 candidate genes or genomic regions on all chromosomes [6-8], we also mention the genes directly involved in regulating the aspects of carbohydrate metabolism that are relevant to obesity.

The overall aim of this review is to provide evidence that can be used to compile adequate dietary guidelines for the general population and for individuals at risk of diabetes and cardiovascular diseases. 
Table 1. Classification of Carbohydrates According to their Chemical Structure

\begin{tabular}{|c|c|c|}
\hline Class (DP*) & Sub-Group & Components \\
\hline \hline Sugars (1-2) & Monosaccharides & Glucose, galactose, fructose, mannose, tagatose \\
\hline & Disaccharides & Sucrose, lactose, trehalose, maltose, isomaltulose \\
\hline Oligosaccharides (3-9) & Polyols & Maltodextrins \\
\hline & Malto-oligosaccharides & Raffinose, stachyose, fructo-oligosaccharides, galacto-oligosaccharides \\
\hline Polysaccharides (>9) & Other oligosaccharides & Amylose, amylopectin, modified starches, glycogen \\
\hline & Starch & Cellulose, hemicellulose, pectins, hydrocolloids \\
\hline
\end{tabular}

$\mathrm{DP}^{*}=$ Degree of polymerization. Adapted from FAO Corporate Document Repository: Carbohydrates in Nutrition

http://www.fao.org/docrep/W8079E/w8079e07.htm

We first give a brief summary of the nomenclature, structure and metabolism of the major dietary carbohydrates.

\section{Classification of Carbohydrates}

Based on their chemical structure, carbohydrates $(\mathrm{CHO})$ are classified according to the degree of polymerization into sugars, oligosaccharides and polysaccharides (Table 1).

Other nomenclatures refer to metabolic pathways and physiological effects. Carbohydrates that provide the body with monosaccharides for metabolism are defined as glycemic, digestible or available. Metabolizable $\mathrm{CHO}$ can be further subdivided according to their capacity to increase blood glucose. This metabolic outcome is dependent on the food matrix and the relative content of complex versus simple sugars, the use of modified or resistant starches, cooking methods and various effects of food processing. Sugars added during the manufacturing processes are classified as added or extrinsic sugars, to distinguish them from those that are naturally present in foodstuffs (intrinsic) and in milk.

However, chemical structure and the above-mentioned characteristics do not wholly explain the nutritional effects of $\mathrm{CHO}$ on health. This difficulty together with the lack of consensus on the classification of carbohydrates in different food matrices has compromised the interpretation of results from clinical studies and undermined attempts to establish causal links with metabolic alterations. This lack of solid evidence still hampers the compilation of adequate dietary guidelines. The current trend is to take into account modulation by other nutrients and to view foodstuffs as part of a global nutritional profile with specific functional and health consequences [9].

\section{The Importance of Carbohydrates and Glucose as Fuel: Implications for Disease Risk}

Glucose supplies nearly half of the 150-300 moles of ATP needed daily and, in basal physiological conditions, contributes to $99 \%$ of the energy expenditure in the brain. [10]. For these reasons glucose metabolism is exquisitely regulated in the human body and blood glucose levels are maintained within strict limits: lower than $10 \mathrm{mmol} / \mathrm{L}(180$ $\mathrm{mg} / \mathrm{dL}$ ) to avoid the serious toxicity of elevated glucose, as occurs in diabetes mellitus, and higher than $2.2 \mathrm{mmol} / \mathrm{L}$ (40 $\mathrm{mg} / \mathrm{dL}$ ), to supply the brain with around the 100-200 gram glucose it needs daily to avoid hypoglycemic complications.
This is achieved by a fine balance between on the one hand glucose uptake into the tissues and on the other, entry into the blood stream from either the liver or from the gut (after meals). The liver supplies blood glucose from either its modest stores of glycogen (less than 100 gram) or via gluconeogenesis, which can supply up to two-thirds of blood glucose during the post absorptive and fasting states. As regards the supply via the gastro-intestinal tract, the major dietary $\mathrm{CHO}$, except for mannose and fructose, are first converted into glucose before further metabolic use (Fig. 1).

Thus dietary $\mathrm{CHO}$ are not in a strict sense essential nutrients. Nevertheless, their intake, by changing blood glucose patterns, affects insulin secretion directly and can thus have an important and immediate impact on diurnal human metabolism. Consequently, glycemic metabolism is especially susceptible to dietary $\mathrm{CHO}$-induced alterations, with potential pathologic consequences that can lead to obesity, diabetes mellitus and cardiovascular disease.

This pathogenic potential periodically attracts renewed interest, which often coincides with the introduction of novel $\mathrm{CHO}$ in food. It is also interesting to note that in contrast to substantial differences in the intakes of fats, protein, fibers, vitamin $\mathrm{C}$ and sodium, the proportion of energy provided by $\mathrm{CHO}$ is only slightly lower (around $35 \%$ of the total daily energy intake) in the Paleolithic than the Modern diet ( $>$ $40 \%$ ). The main difference lies in the sources of carbohydrates (fruits and vegetables, with $3 \%$ honey in the Paleolithic in contrast to cereal and dairy and $25 \%$ energy from added sugars in the Modern diet $[11,12])$. Later on in history, the discussions on the role played by $\mathrm{CHO}$ compared to fats evolved in parallel to the increase in sugar consumption after its introduction into Europe by Napoleon in 1815 and the subsequent industrial processing of foodstuffs [13]. More recently, the interest has centered on the intensive use of added $\mathrm{CHO}$ in foods and sweetened beverages in relation to the current obesity and diabetes epidemic and the emerging evidence on the efficacy of weight-loss diets that are low in CHO [14-16].

In the next two sections, we analyze the following question: "To what extent is obesity and its complications determined by the amount and/or by the type of carbohydrates in the diet?" 


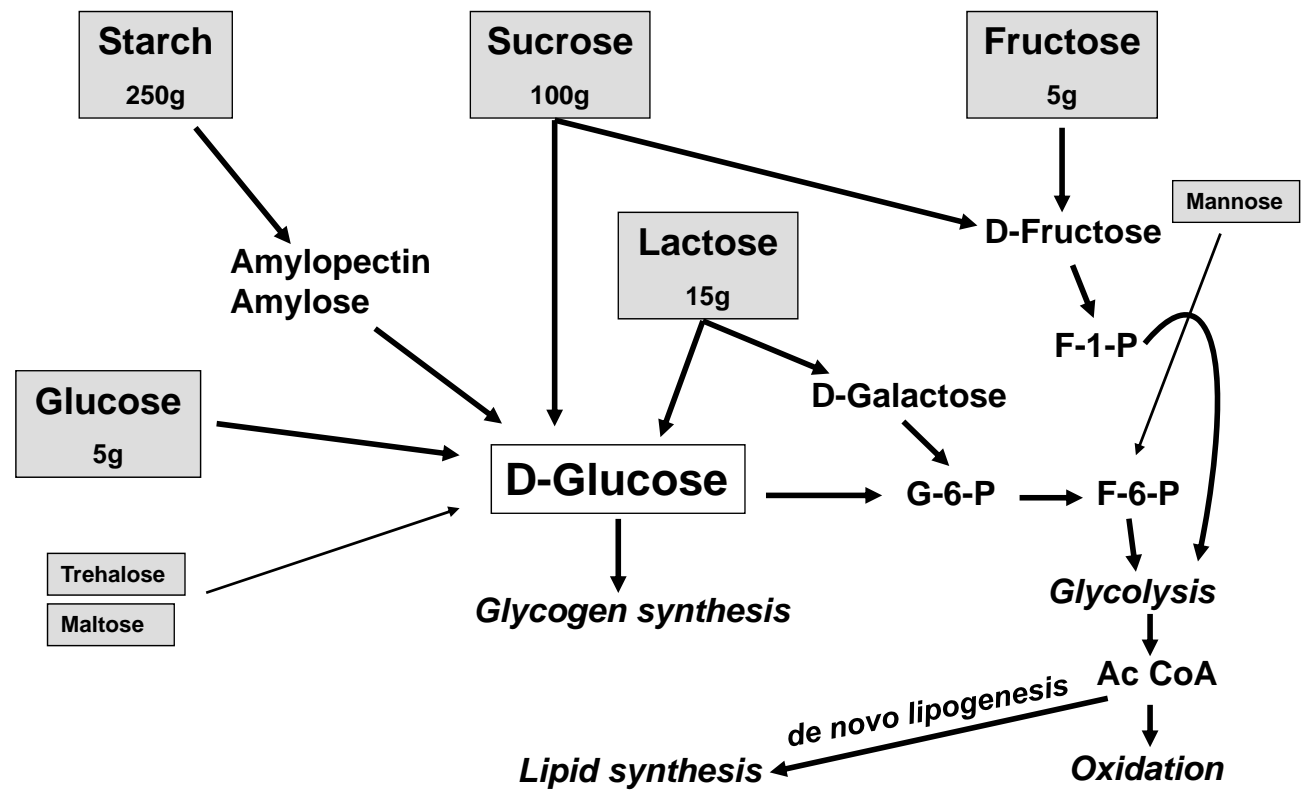

Fig. (1). Metabolism of Dietary Carbohydrates (CHO).

Glucose is the key converging molecule and about 300 gram are metabolized each day. In this review we focus on the impact of CHO with different glycemic index and content in sucrose and fructose, on metabolic changes, such as de novo lipogenesis, that may result in obesity and its complications. Abbreviations:G-6-P, glucose -6-phosphate; F-1-P fructose-1-phosphate; F-6-P, fructose -6-phosphate; Ac CoA, acetyl coenzyme A.

\section{QUANTITY OF CARBOHYDRATES IN THE DIET}

\section{De Novo Lipogenesis from Carbohydrates?}

The first question to ask is if the relative proportion of $\mathrm{CHO}$ compared to fat affects accumulation of body lipids. The relevance of this question was highlighted by studies showing that high $\mathrm{CHO}$ diets led to increases of serum triacylglycerol in both animals and humans $[17,18]$. The "Carbohydrate Induction Theory" postulated that excess dietary CHO (i.e. those not used to generate energy or to replenish glycogen stores) would be converted into lipids via the metabolic pathways of de novo lipogenesis that takes place mainly in liver and adipose tissue (Fig. 1). This, together with a decrease in fat breakdown (lipolysis), would be the direct consequence of the rapid increases of insulin that accompany CHO-rich meals [16]. A few relevant examples of classical studies are summarized here. First, the increase in serum triacylglycerol triggered by a high $\mathrm{CHO}$ diet is not permanent as shown by Antonis in a pioneer experiment where a high caloric (3000 Kcal daily), high fat $(40 \%$ energy) diet was replaced by a high $\mathrm{CHO}(15 \%$ energy from fat) diet with the same total amount of calories. After 5 weeks, serum triacylglycerol had increased, sometimes even doubled. However, in the subsequent 6 months of the same high $\mathrm{CHO}$ diet, fasting serum triacylglycerol gradually returned to the initial values. It should be noted that this experiment did not provide any information on diurnal triacylglycerol variations or on changes in body fat [19]. Second, massive CHO feeding (4800 Kcal, $86 \%$ energy from $\mathrm{CHO}$ ) for 7 days first saturated glycogen stores (to a maximum of 15 gram $/ \mathrm{kg}$ body weight). The extra $\mathrm{CHO}$ were oxidized and a limited amount was converted into fats which increased by 150 gram /day [20]. Isotopic studies to trace the incorporation of labeled $\mathrm{CHO}$ atoms into VLDL in the liver, demonstrated an increase in VLDL synthesis (from 2 to 10 gram/day) and a mean fat balance of 275 gram after 96 hours of overfeeding (by $50 \%$ with $\mathrm{CHO}$ ). This corresponds to a $2-$ 3 -fold increase in de novo lipogenesis [21]. More recent studies show that in eucaloric diets with a high proportion of $\mathrm{CHO}$, the increase in serum triacylglycerol is mainly due to its decreased clearance (uptake and oxidation) in peripheral muscle [22]. As regards synthesis, the incorporation of fatty acids arising from de novo lipogenesis into VLDL increases in high $\mathrm{CHO}$ diets [23]. It is now also recognized that glucose directly regulates the transcription of genes responsible for fatty acid synthesis and oxidation [24]. The net impact of clearance versus synthesis on serum triacylglycerol levels is highly variable and strongly determined by many factors such as duration of the dietary intervention, fed versus fasted, diurnal patterns, type of $\mathrm{CHO}$, as well as baseline conditions such as BMI, insulin levels and sensitivity, triaclyglycerol levels and genetic factors [25].

In conclusion from these studies and based on the metabolic concepts outlined in the last 15 years $[4,5]$ it can be summarized that the metabolic fate of $\mathrm{CHO}$ is determined by both the total caloric content of the diet and the proportion of macronutrients (Fig. 2: see legends for a more detailed description).

In mixed eucaloric diets (Fig. 2A) energy is obtained from both $\mathrm{CHO}$ and fats. Conversion of $\mathrm{CHO}$ to body fat is energetically expensive $(12 \%$ compared to only $3 \%$ in the case of dietary fats) and is limited. In eucaloric diets with high proportions of $\mathrm{CHO}$ (Fig. 2B) both oxidation of glucose and conversion to glycogen are increased and some de novo lipogenesis can take place, depending on multiple factors (see above). The inverse situation, a eucaloric diet with a low to very-low content in $\mathrm{CHO}$, usually contains a high proportion of calories from fat since the caloric contribution from protein can seldom rise above 30-35\%. After 6 weeks of a very low $\mathrm{CHO}$ eucaloric diet $(8 \%$ energy from $\mathrm{CHO}$ 
A.

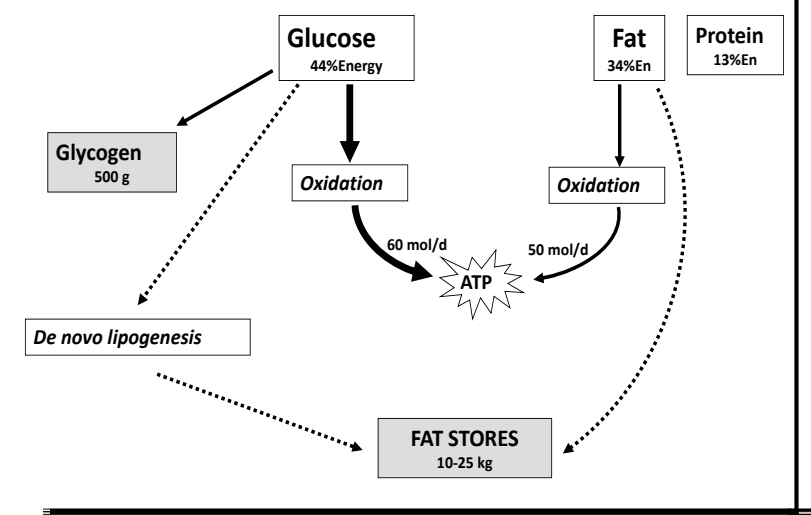

C.

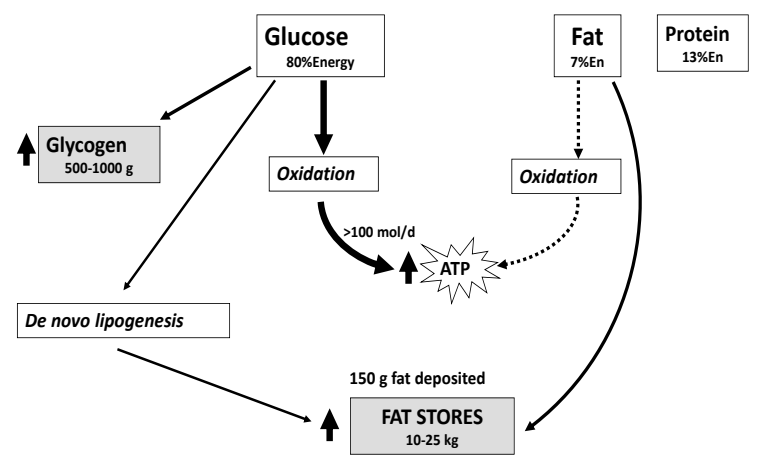

B.

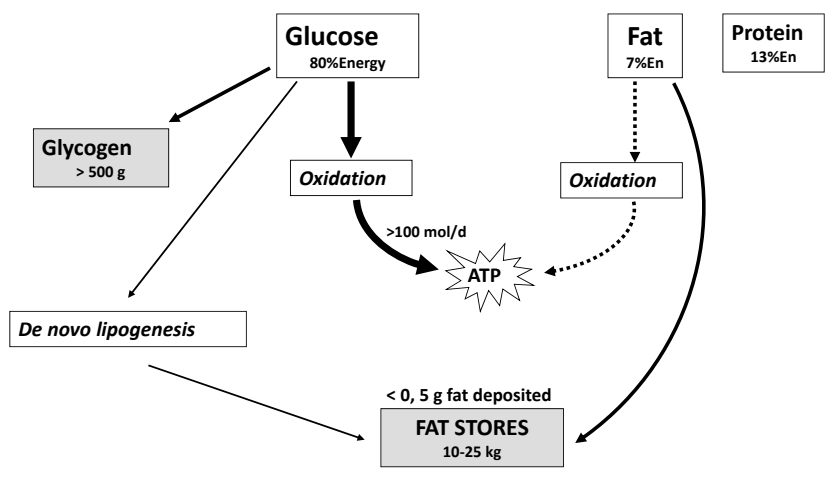

D.

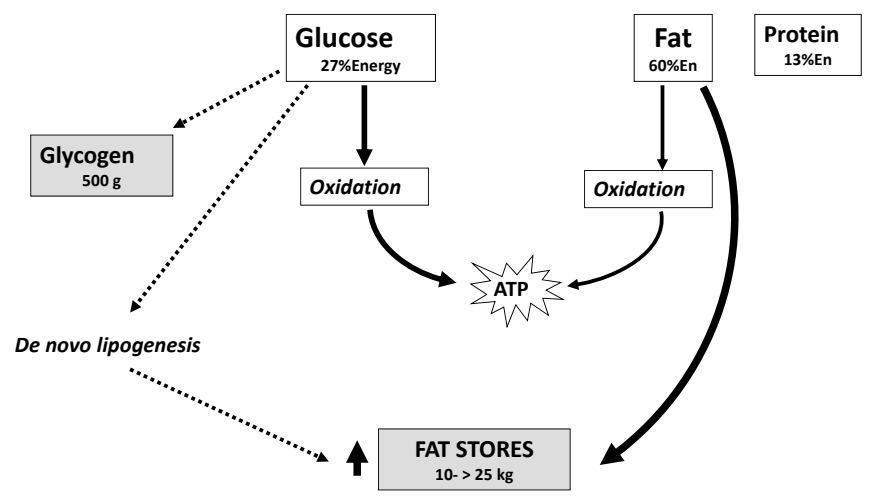

Fig. (2). Metabolic Fate of Carbohydrates and Fats After Meals.

A. Balanced mixed eucaloric diet. Glucose is preferentially oxidized and produces approximately half of the energy needed. The rest is used for replenishment of glycogen stores. In second place, all the fatty acids from the ingested fat are oxidized to produce the remaining energy needed. Since the ingestion of nutrients is balanced to expenditure, it contains no excess of calories and there is negligible deposition of fat.

B. Eucaloric diet with a high proportion of carbohydrates. Energy expenditure does not change and a higher proportion of the energy is produced by $\mathrm{CHO}$ oxidation. The remaining glucose is used to produce glycogen and there is moderate de novo lipogenesis but no net deposition of body fats.

C. Hypercaloric diet with an excess of carbohydrates. Energy expenditure and glucose oxidation increase. Excess glucose is used to load glycogen stores to saturation (about 500 gram higher than in normal diets) and the rest converted to fat by de novo lipogenesis. Since glucose is preferentially oxidized, less fat will be oxidized, leaving an excess that will be deposited as body fat stores. In this way, dietary fats form the main source of body fat deposition.

D. Hypercaloric diet with an excess of fat. Glucose and fat oxidation rates do not change. The excess in dietary fat is thus wholly converted into body fats.

compared to a habitual $48 \%$ ) lean men lost an average of 3 $\mathrm{kg}$ body fat mass and this loss was mainly determined by the change in insulin levels [26]. The metabolic effects of eucaloric diets differing in the proportion of $\mathrm{CHO} /$ fat/protein have often been studied in weight-maintenance or ad libitum conditions, often after a hypocaloric weight-loss period. One important conclusion of these studies is that the rate of weight regain was similar but that beneficial changes in insulin sensitivity and serum lipids were determined by the proportion of mono unsaturated fats and protein $[27,28]$. The impact of CHO type in weight-maintenanceand other diets is discussed in the following sections.

In hypercaloric diets caused by an excess of $\mathrm{CHO}$ (Fig. 2C), de novo lipogenesis will occur after a maximal amount of glucose is oxidized or converted to glycogen. Fat deposition is mainly provided by the relative excess of dietary fats since these are oxidized to a lesser extent. In the hypercaloric diets caused by an excess of fats (Fig. 2D), fat oxidation rates do not increase immediately and the caloric excess in the form of dietary fat is almost totally converted into body fat, which has an almost limitless storage capacity. Subsequent trafficking of fuels between tissues, for example when the energy balance is negative (between meals), will release fatty acids from adipose tissue and preferentially redistribute this fat fuel to metabolically active tissues such as liver and skeletal muscle for oxidation [29]. Indeed high fat diets have been shown to induce increases in fat oxidation in skeletal muscle during subliminal exercise and consequently, fat loading is a strategy used in endurance training [30]. The situation under pathological conditions such as obesity is discussed in the section "Modifying Factors".

Though this review does not discuss the metabolic consequences of hypocaloric diets with different proportions of $\mathrm{CHO}$, fats and proteins, it should be mentioned here that the 
metabolic consequences of changing macronutrient proportion during negative energy balance do not necessarily mirror the four situations of (positive or neutral) energy balance described above. Indeed, hypocaloric diets with very low carbohydrates $(12 \%$ energy) in obese subjects lead to greater increases in markers of lipolysis (ketones and free fatty acids) together with greater decreases of markers of lipogenesis (incorporation of palmitoic acid in triglycerides) and deposition of body fat (leptin) when compared to low-fat (56\%energy as $\mathrm{CHO}$ ) hypocaloric diets. These effects are accompanied by improvements in insulin sensitivity and a less atherogenic serum lipid profile [16]. However, in this diet the lowering in the proportion energy from carbohydrates is accompanied not only by an increase in energy contribution from fat (from 24 to $59 \%$ ) but also from protein (from 20 to 28\%). It should be noted that low $\mathrm{CHO} /$ high protein weight-loss diets, independently of fat, improve body fat mass control [31]. The impact of micronutrient and alcohol content in these diets is also significant and the subject of other reviews.

\section{Appetite Control and Palatability}

In addition to the changes in glucose and fat metabolism outlined above, differences in the proportion of ingested $\mathrm{CHO}$, protein and fat can affect appetite control and thus caloric intake by various pathways. Supplementing a meal with extra calories as $\mathrm{CHO}$ suppresses hunger in the first 1 to 3 hours more effectively than when the extra energy is in the form of fat [32]. Several mechanisms have been proposed. In addition to the hormonal responses to stomach filling and to post-meal changes in blood glucose, amino acids and triglycerides, specific glucose sensors in liver and brain are directly involved in the regulation by the hypothalamus of feeding and the sensations of hunger and satiety. Lipid induced dysregulation of glucose sensing would, by disrupting both the secretion of insulin as well as the suppression of glucagon in the fed state, block the signals that are necessary to stop excessive feeding. The ensuing uncontrolled appetite may well be one of the earliest manifestations in the pathogenesis of obesity [33]. It should be stressed that translation of these short-term studies to the free-living habitual situation has so far not been consistent and that it is incorrect to conclude that high carbohydrate diets protect against excessive energy intake in the long-term [34]. Other effects that are inherent to dietary $\mathrm{CHO} /$ fat proportion such as bulk, meal matrix and protein and fiber content are primarily determined by the quality of fat or $\mathrm{CHO}$ (discussed in the following sections). And finally, the responses of individuals to the pro-obesigenic setting of high food palatability are highly variable.

\section{Modifying Factors}

It should be stressed that the scenarios described above do not apply to pathological situations associated with severe hormonal imbalances such as, for example, acute intravenous glucose re-feeding in malnutrition or in obese patients with different degrees of insulin resistance [4]. For example, trafficking of substrates between tissues differs. In lean subjects preferential delivery of fat to metabolically active tissues such as liver and skeletal muscle favors fat oxidation whereas in obese subjects dietary fat is preferentially delivered to adipose tissue and stored as body fat. Thus sensing of excess energy and coupling to dietary intake are impaired in obesity prone individuals. The failure in liver and muscle to increase fat uptake and oxidation rates in response to increased fat intakes is caused in part by the insulin resistance of the obese phenotype $[29,35]$.

Moreover, the individual responses to different $\mathrm{CHO}$ content of diets are extremely variable. Gene polymorphisms or mutations can affect $\mathrm{CHO}$ metabolism in general and/or in response to specific types and quantities of CHO. Recent discovery of linkage between obesity and the PFKFB3 (6phosphofructo-2-kinase/fructose-2,6-bisphosphatase 3) gene and of lower mRNA levels of this enzyme in adipose tissue of obese women, indicates that regulation of glycolysis can play a fundamental role in the susceptibility to the changes in CHO metabolism that promote obesity [36]. The impact of the genotype can also be modulated by the quantity of $\mathrm{CHO}$. For example in women, the Gln27Glu polymorphism of the beta-2 adrenoceptor is associated with a doubled risk of obesity when the diet contains more than $49 \%$ energy as $\mathrm{CHO}$ [37]. Similarly, the obesity risk associated with the Pro12Ala polymorphism of the PPAR gamma gene differs with the CHO intake [38]. Finally, the rs2297508 polymorphism of the SREBP-1c (sterol regulatory element binding protein-1c) gene modulates the impact of high $\mathrm{CHO}$ diets on dyslipidemia and insulin sensitivity [39]. These gene/metabolism relationships are strongly modulated by gender. For example, women differ significantly from men in nutrient handling, fat oxidation/lipolysis rates, lipoprotein turnover and body fat distribution, as reviewed extensively elsewhere [40].

It should be noted that in the above-mentioned studies the increase in dietary $\mathrm{CHO}$ was often achieved by adding sugared drinks or not clearly specified $\mathrm{CHO}$, in this way also changing the balance between the different types of $\mathrm{CHO}$ in the diet. This distinction was initially not taken into account when analyzing the impact of $\mathrm{CHO}$ quantity on body fat deposition but, as seen in the next section, the specific metabolic effects of each type of CHO can have important consequences on the appearance of obesity and its complications [41].

\section{QUALITY OF CARBOHYDRATES IN THE DIET}

Since the functional and metabolic effect of a given $\mathrm{CHO}$ cannot be simply extrapolated from its chemical structure, several parameters have been proposed to measure $\mathrm{CHO}$ quality based on its effects on glucose absorption and its metabolic use. In this review we concentrate on the capacity to alter blood glucose levels and on the specific effects of added sugars containing sucrose and fructose.

\section{Glycemic Index and Load}

The concept of glycemic index (GI) has been in use for more than 25 years $[42,43]$ and its validity repeatedly reviewed and questioned [44, 45]. It is defined as the 2-hour incremental area under the glucose response curve after a standard amount $(50 \mathrm{~g})$ of available CHO of a test food relative to that of a control food (white bread or glucose). An impressive amount of work has been dedicated to compile tables with the GI of foods, taking into account not only the type of $\mathrm{CHO}$ but also the influence of processing, cooking, amount of the servings (glycemic load) and content in fiber and other foodstuffs [46]. The methodology, problems of 


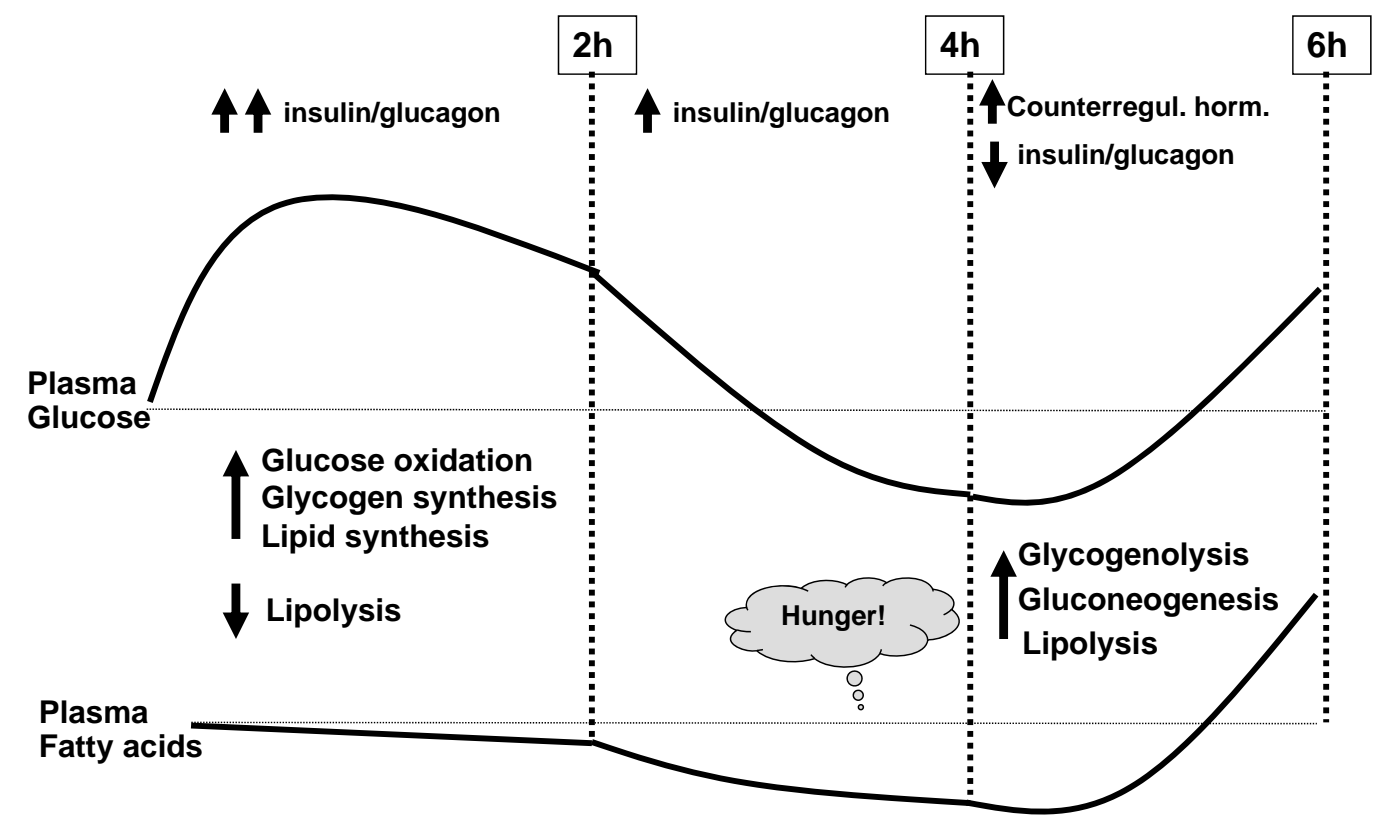

Fig. (3). Metabolic Events after the Ingestion of a Meal with a High Glycemic Index.

In the first 2 hours, the excessive and often rapid increase in blood glucose will trigger an abnormal increase of insulin and a decrease of glucagon secretion. The insulin/glucagon imbalance in favor of insulin stimulates the metabolic pathways that utilize glucose (glucose oxidation, glycogen synthesis and lipid synthesis) and inhibits lipolysis. The persistence of this hormonal imbalance causes an excessive decrease of blood glucose and free fatty acids (2-4 hours). This phenomenon of postprandial hypoglycemia is accompanied by a strong sensation of hunger. These alterations also trigger rebound increases of glucagon and other counter regulatory hormones with a reversal of the insulin/glucagon balance and stimulation of glucose-releasing pathways (glycogenolysis and gluconeogenesis) and of lipolysis. As a result, blood glucose and fatty acids again increase abnormally in the late postprandial phase (4- 6 hours). These exaggerated fluctuations thus prolong the duration of hormonal imbalances.

intra- and inter-individual variability, need of standardization and clinical utility in obesity and diabetes have been recently reviewed [47, 48].

In essence, the glycemic index (and its derived parameter the glycemic load) is an attempt to quantify the capacity of a $\mathrm{CHO}$ or meal to increase blood glucose. It is widely acknowledged that alterations in the pattern and degree of glucose increase can trigger both acute and chronic metabolic abnormalities that favor obesity and diabetes [44]. The acute changes after a meal with a high GI are outlined in Fig. (3).

The abnormally high postprandial blood glucose triggers imbalances between on one hand the insulin and on the other glucagon and eventually also the other counter regulatory hormones. As a result, there are excessive fluctuations and a postprandial fall in the concentration of blood glucose and free fatty acids. This scenario is accompanied by insufficient postprandial satiety and often leads to increased voluntary consumption of high-energy foods. For example, in obese children, increasing the GI of oatmeal without modifying the proportion of macronutrients by using instant instead of steel-cut oats, resulted in a $53 \%$ increase in caloric intake [49]. In the long-term, this craving for high-energy foods can become a habit that often results in weight gain. Moreover, the repeated metabolic imbalances lead to a state of hyperinsulinism and insulin resistance with elevated plasma triacylglycerol and deposition of body fat, as well as causing toxic damage in the pancreatic $\beta$-and endothelial cells. These chronic changes favor the development of obesity, diabetes and cardiovascular disease, as outlined in Fig. (4).
The underlying changes at the sub cellular level are being gradually identified. A recent investigation (FUNGENUT) detected differences in gene expression in subcutaneous fat tissue of patients with metabolic syndrome after 12 weeks of either a low or a high glycemic index diet. Although there were no changes in body weight in either group, in the low GI group 71 genes linked to insulin signaling, such as for example insulin receptor, insulin-like-growth-factor binding protein 5 and hormone sensitive lipase, were downregulated. In this group there was also an improvement in the insulingenic index (ratio of the increment of insulin /increment of glucose in the first 30 minutes of an oral glucose tolerance test) a measure of early insulin secretion that is altered in the first stages of glucose intolerance [50].

The pathophysiological hypothesis proposing a causal link between a high GI diet and obesity, diabetes and cardiovascular disease has been tested in cross-sectional and longitudinal epidemiological studies. Table 2 shows a summary of prospective cohort studies investigating the risk of developing type 2 diabetes. Except for two studies both conducted on elderly subjects, the multivariate adjusted risk was higher by 21 to $59 \%$ when comparing the highest to the lowest quintile of GI.

Meta-analysis of intervention studies examining the impact on markers of metabolic control have confirmed that low-glycemic diets favor a greater weight-loss as well as better lipid and glycemic control $[59,60]$ and a lower incidence of diabetes [61]. In practical terms, these studies indicate that a two-serving increment in whole-grain consump- 


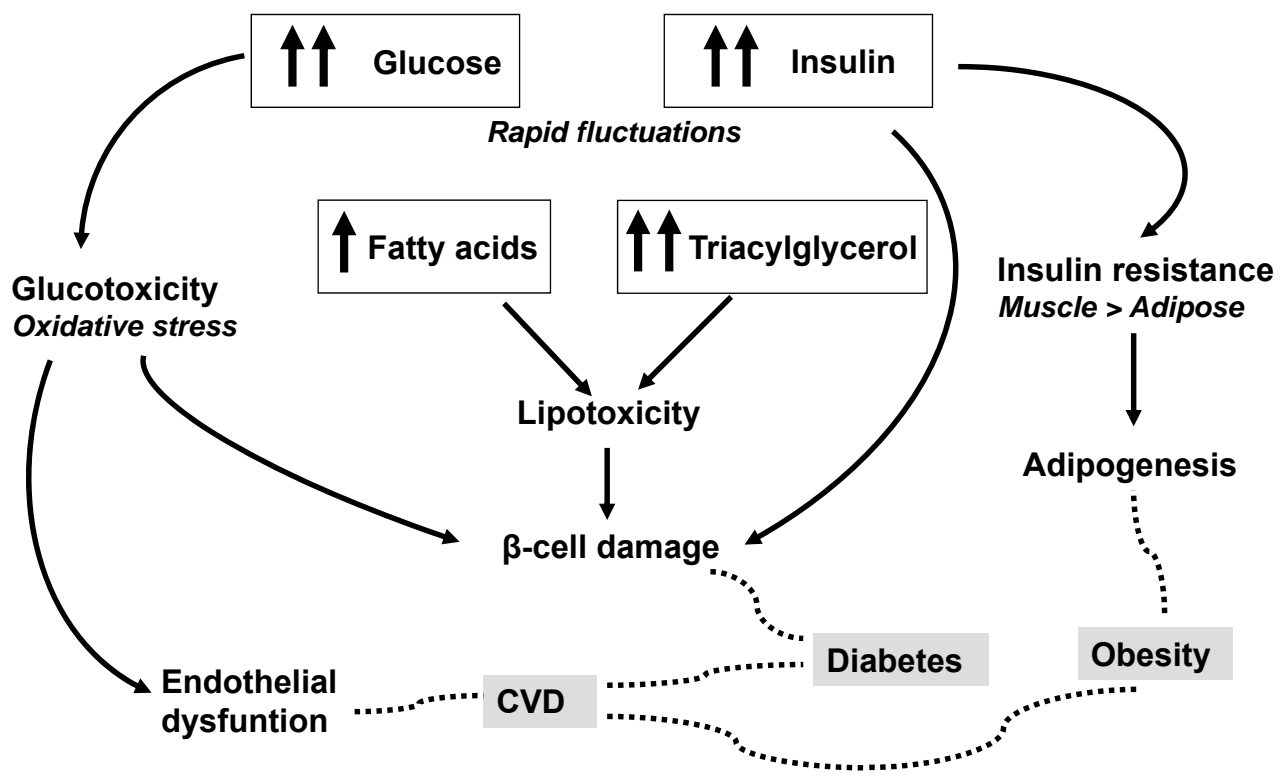

Fig. (4). Long-Term Metabolic Effects of a Diet with a High Glycemic Index.

The frequent state of hyperinsulinemia causes a state of insulin resistance that is more pronounced in muscle than in adipose tissue thus favoring a redistribution of metabolites to the adipocyte and deposition of body fat. The rapid fluctuations and increases in glucose and fatty acids are directly toxic to both the $\beta$ cell in the pancreas and the endothelial cell in the vasculature. These alterations can account for a higher incidence of obesity, diabetes and cardiovascular disease (CVD).

Table 2. Prospective Cohort Studies on the Relationship Between Dietary Glycemic Index and Incidence of Type 2 Diabetes Mellitus

\begin{tabular}{|c|c|c|c|c|}
\hline Name of Study & $\begin{array}{c}\text { Subjects } \\
\text { (age) }\end{array}$ & $\begin{array}{l}\text { Duration } \\
\text { (follow-up) }\end{array}$ & Findings & Reference \\
\hline Nurses Health Study & $\begin{array}{c}65173 \text { women } \\
(40-65 \mathrm{yr})\end{array}$ & 6 years & $\begin{array}{l}\text { RR of highest/lowest quintile GI }=1.37[1.09-1.71] \\
\text { Protection by cereal fiber }\end{array}$ & Salmeron [51] \\
\hline $\begin{array}{l}\text { Health Professionals } \\
\text { Study }\end{array}$ & $\begin{array}{l}42759 \mathrm{men} \\
(40-75 \mathrm{yr})\end{array}$ & 6 years & $\begin{array}{l}\text { RR of highest/lowest quintile GI }=1.37[1.02-1.83] \\
\text { Protection by cereal fiber }\end{array}$ & Salmeron [52] \\
\hline Melbourne Collaborative & $\begin{array}{l}36787 \text { men \& women } \\
(40-69 \mathrm{yr})\end{array}$ & 4 years & $\begin{array}{c}\text { OR per } 10 \text { GI units }=1.32[1.05-1.66] \\
\text { Protection by total } \mathrm{CHO} \text {, sugar, magnesium }\end{array}$ & Hodge [54] \\
\hline $\begin{array}{l}\text { Healthy Aging \& Body } \\
\text { Composition }\end{array}$ & $\begin{array}{l}1898 \text { men \& women } \\
(70-79 \mathrm{yr})\end{array}$ & 4 years & $0 \mathrm{R}$ of highest/lowest quintile $\mathrm{GI}=1.0[0.5-2.0]$ & Sahyoun [57] \\
\hline $\begin{array}{l}\text { Shanghai Women's } \\
\text { Health }\end{array}$ & $\begin{array}{c}64227 \text { women } \\
(40-70 \mathrm{yr})\end{array}$ & 4.6 years & $\begin{array}{l}\text { RR of highest/lowest quintile GI }=1.21[1.03-1.43] \\
\text { Higher risk with rice intake }\end{array}$ & Villegas [58] \\
\hline
\end{tabular}

Some examples of published studies examining the association between a diet with high glycemic index and the incidence of type 2 diabetes mellitus are shown. Results are expressed as multivariable adjusted relative risk (RR), odds ratio (OR), incidence rate ratio (IRR), with $95 \%$ confidence intervals between square brackets

tion is associated with a $21 \%$ decrease in the risk of developing type 2 diabetes mellitus [62]. A decrease in glycemic load of 17 gram of glucose equivalents daily is also associ- ated with favorable decreases in fasting triacylglycerol and body weight. It should be noted, however, that the benefit is more pronounced in subjects with impaired baseline metabo- 
lism [63] and could not be confirmed in all studies [64]. It is also evident that low GI and glycemic load diets are often achieved by decreasing total CHO intake as evidenced by the positive associations between GI and dietary $\mathrm{CHO}$ even after energy adjustment [57]. Thus it was not always possible to differentiate from the beneficial effects of lowering total $\mathrm{CHO}$ (see above) and thus increasing the proportion of dietary protein and fat. Moreover, the associated changes in fiber composition, food matrix, fructose content (see below) and in general other nutrient composition have independent metabolic effects that complicate the analysis of those specifically caused by the lowering of GI [45]. In the recently completed European DIOGENES study, where the aforementioned factors were carefully controlled for, the lowering of GI by 4.7 units that was achieved resulted in a significantly lower weight regain [65].

\section{Sucrose Versus Starch}

In 1972, John Yudkin first published his bestseller "Pure, White and Deadly!" [66]. And the terms "empty calories" (at that time referring mainly to sugar), "added" or "extrinsic" sugars, acquired widespread use in nutritional discussions.

Based on animal studies, Ahrens proposed in 1974 a mechanistic hypothesis to explain the potential pathobiochemical effects of sucrose. The increase in caloric intake and fluid retention would lead to obesity and hypertension as well as to a deterioration of liver function and eventually to the development of a fatty liver. The resulting impairment of mitochondrial respiration and subsequent lowering of the $\mathrm{ATP} /(\mathrm{ADP}+\mathrm{AMP})$ ratio would lead to an increase in purine conversion to uric acid. The decrease in VLDL clearance by the liver would cause an increase in blood triacylglycerol [17]. These alterations have since been recognized as components of the metabolic syndrome [67].

Subsequent observational epidemiological human studies have, however, been unable to establish a direct association between sugar consumption and obesity. In the MONICA and Scottish Heart Health studies, the median sugar intake was similar across the BMI spectrum of study subjects and there was even an inverse relationship between quintiles of extrinsic sugar consumption and prevalence of obesity [68]. In the Dietary and Nutrition Survey of British Adults the negative relationship between sugar intake and BMI was only found in men but not women [69]. Moreover, crosscountry studies have revealed a reciprocal relationship between the intakes of fats and sugars (but not complex carbohydrates) when examining their percent contribution to total energy intake. This observation underscores the natural preference to consume energy-rich foods regardless of their source. In other words, the excess energy is either supplied by sugars when fats are less available or by fats in case of fat oversupply [70].

The available evidence is also insufficient to establish a direct causal link between sugar intake and obesity [71]. Intervention studies, either ad libitum or hypocaloric, comparing the impact of substituting sucrose by starch did not detect any significant differences in weight loss $[72,73]$ despite the fact that starchy diets give better satiety. Prospective and intervention studies also failed to find any association between high sucrose diets and insulin resistance or risk of type 2 diabetes $[74,75]$. In non-medicated type 2 diabetic patients on a weight-maintenance diet and receiving the same total amount of $\mathrm{CHO}$ in the form of either sucrose or complex $\mathrm{CHO}$ for one month, glucose and lipid parameters did not differ, but postprandial insulin was lower in the low sucrose $\operatorname{diet}[76]$.

Notwithstanding these observations, there is still not enough evidence to reject the 30-year-old hypotheses of Yudkin and Ahrens on the capacity of added sugars to cause metabolic alterations that may predispose to obesity in case of exposure to a high fat diet. Longer-term and higherpowered studies will be needed in order to reveal the real differences in the obesigenic capacity of "high fat" compared to "high fat sweet foods".

\section{Sweetened Beverages with High Fructose Corn Syrup and the Diabesity Epidemic}

Two observations re-awakened the debate on $\mathrm{CHO}$ quality but shifted the interest from sucrose to other added sweeteners. It was observed that as a result of nutritional campaigns warning about the unhealthy effects of fats, consumption of dietary fat in the USA decreased from $>40 \%$ in 1965 to $\sim 33 \%$ of energy intake in 1995 [77]. Despite this improvement, obesity and type 2 diabetes have continued to increase exponentially during this period. This "diabesity epidemic" has occurred in parallel with the consumption of sweetened soft drinks [78]. A recent meta-analysis has discovered a more than $20 \%$ increased risk of metabolic syndrome and type 2 diabetes mellitus in the highest sweetened beverage consumers [79]. Furthermore, dyslipidemia (decrease in HDL cholesterol and increase in triglycerides) is linearly related to the consumption of added sugars [80].

One possible explanation is that $\mathrm{CHO}$ in sweet beverages do not induce satiety to the same extent as solid forms of CHO [81]. Interestingly, however, diabesity was not associated with fruit juice consumption [82]. This is in sharp contrast to the strong association with the use of corn syrup as a sweetener, in particular that containing a higher proportion $(55 \%)$ of free, unbound fructose (high fructose corn syrup, HFCS) $[78,83]$. Whereas fructose consumption from natural sources has remained constant or decreased, the proportion of sweeteners consisting of HFCS has doubled in the last 30 years [84].

Apart from differences in the rate of gastro-intestinal absorption, excessive fructose consumption can have several metabolic consequences which are unsurprisingly similar to those proposed so many years ago by Ahrens with regard to sucrose and the metabolic syndrome.

\section{Metabolic Effects of Fructose: Fructose Index?}

As outlined in Fig. (5), fructose metabolism differs from that of glucose in several fundamental aspects. An increase in blood fructose levels does not stimulate insulin secretion and fructose has specific phosphorylating (fructokinase) and aldolase(B)enzymes which allow it to enter the glycolytic pathway by-passing the rate limiting steps of glucose- and fructose-6-phosphate- phosphorylation. Moreover, fructose up-regulates enzymes catalyzing fatty acid synthesis [85]. These peculiarities, together with the increased production of glycerol-3-phosphate, favor conversion of fructose into lipids in the form triacylglycerol in the liver [86].The net increase in serum triacylglycerol is de facto higher after acute 


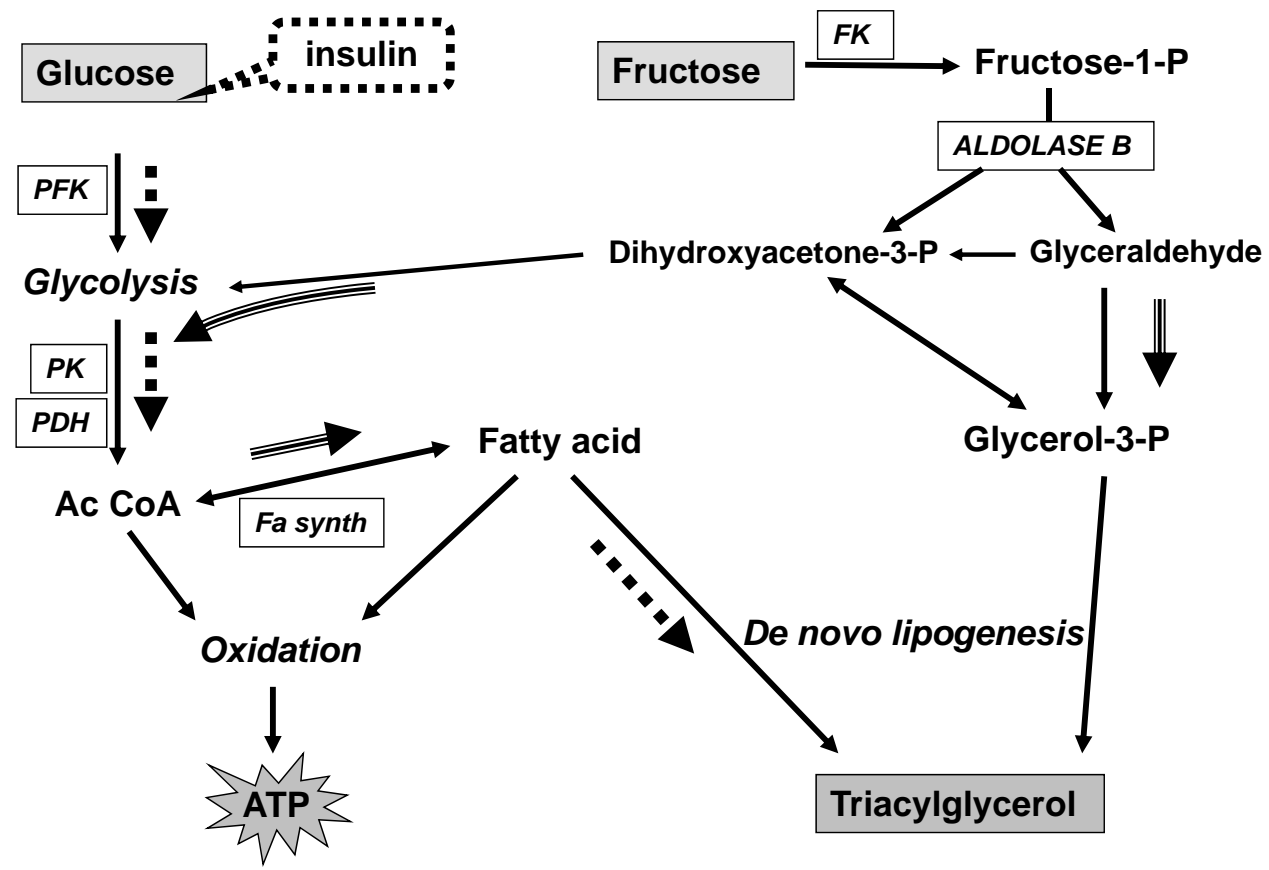

Fig. (5). Metabolism of Fructose.

Fructose is specifically metabolized by fructokinase (FK) and aldolase B to form didhydroxyacetone-3-phosphate and glyceraldehyde. These intermediary metabolites either join the glycolytic pathway or are converted to glycerol-3-phosphate. Fructose also specifically activates enzymes that catalyze the synthesis of fatty acids, thus shifting the use of acetyl coenzyme A (Ac CoA) from energy-production to lipid synthesis (empty arrows). When fructose is ingested together with food or drinks containing glucose, insulin secretion will be stimulated and will activate enzymes such as phosphofructokinase (PFK), pyruvate kinase (PK) and pyruvate dehydrogenase (PDH) that enhance glucose utilization and conversion to fatty acids (dotted arrows). Thus, the presence of fructose channels hexose metabolites towards de novo lipogenesis and, as a consequence, increases triglyceride synthesis and body fat deposition.

intake of pure fructose than after equivalent amounts of glucose [87]. Moreover, co-ingestion of glucose together with unbound fructose (as for example in HCFS), will, by triggering a sharp insulin release, promote lipogenesis even further [86].

The increases in serum triacylglycerol can give rise to further alterations in serum lipids. For example, fructose consumption has been shown to predict smaller LDL particle size in normal and overweight children [88]. However, in healthy men exposed for 6 weeks to high dietary fructose, the increase in serum triacylglycerol was not accompanied by any change in the serum concentration of total and HDL cholesterol [89].

Since these events occur mainly in the liver, the increased de novo lipogenesis will result not only in higher VLDL production but also in the deposition of excess fat inside the hepatocyte and increased synthesis of lipidderived signaling molecules such as diacylglycerol. The resulting mitochondrial dysfunction and the stimulation of a novel protein kinase $\mathrm{C}$ that disrupts the phosphorylation of insulin response proteins, lie at the basis of the hepatic insulin resistance that is observed after week-long high fructose consumption [90] (Fig. 6).

In adipose tissue and skeletal muscle, high-fructose affects the gene expression of enzymes that promote lipid synthesis such as stearoyl-CoA desaturase-1 and acetyl-CoA carboxylase- 2 as well as those that mark early insulin resistance such as glucose transporter- 4 [91]. This response is tissue and hexose-specific as the magnitude of mRNA change differs in visceral and subcutaneous adipose tissue and in response to isocaloric high-glucose. In these ways, high fructose, compared to glucose, will preferentially promote visceral adiposity and insulin resistance [92].

Other long-term consequences of excessive and unbalanced fructose consumption are alterations in the glucose/insulin fasting and postprandial rhythms that disrupt leptin/ghrelin- dependent hunger signaling in the central nervous system and result in excessive appetite. In combination with fructose-induced lipogenesis, this excessive energy intake will further promote body fat deposition and lead to overweight and obesity [93]. Daily intake of one additional sweet drink for 19 months increased the body mass index by $0.24 \mathrm{~kg} / \mathrm{m}^{2}$ in children and adolescents [83].

An additional consequence of fatty liver deposition is increased uric acid production that can, by decreasing nitric oxide bioavailability, inhibit endothelial-dependent vasodilatation and promote hypertension $[94,95]$. In summary, these specific pathobiochemical effects of fructose lead to visceral adiposity, impaired glucose tolerance, hyperinsulinemia, hypertriglyceridemia and hypertension, all features of the metabolic syndrome [96].

Other pathogenic properties of fructose are its higher capacity to glycate proteins and thus to form more advanced glycation products both in vivo and during cooking and food processing. These and the ensuing glycoxidation products can further worsen the pro-oxidant and inflammatory processes that are especially active in cardiovascular disease and diabetes [97]. 


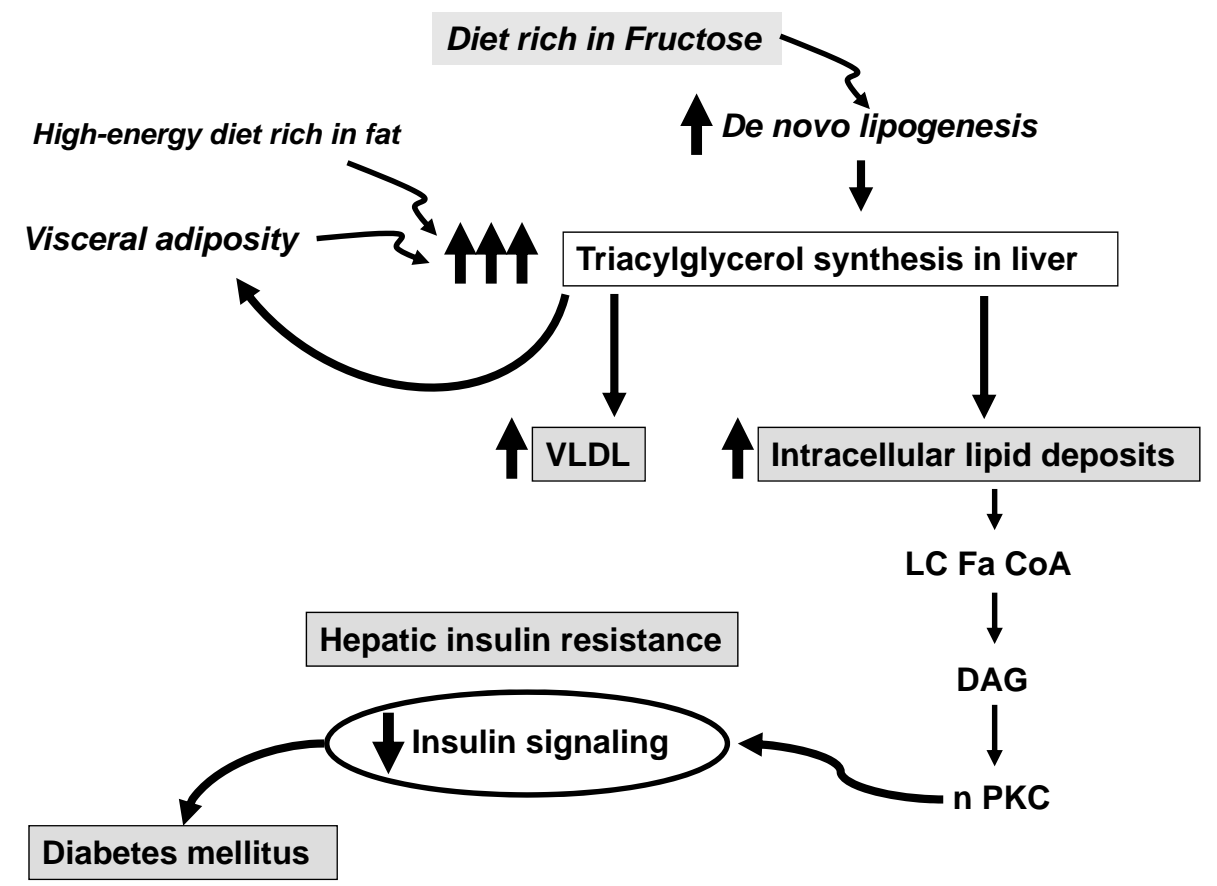

Fig. (6). Long-Term Metabolic Effects of Fructose.

Fructose-induced de novo lipogenesis leads to increased triacylglycerol synthesis, with elevated levels of circulating VLDL and deposition of fat in the abdomen (visceral fat) and in the liver cell (fatty liver). These intracellular fat deposits cause dysfunction of mitochondrial respiration and enhanced liberation of long-chain fatty acid metabolites (LC Fa CoA) and diacylglycerol (DAG). These activate novel protein kinases (n PKC) which interfere with insulin signaling in the cell and thus cause hepatic insulin resistance. Persistence of these alterations is conducive to type 2 diabetes mellitus.

Despite this convincing, though as yet incomplete evidence, it is still too early to designate excessive fructose intake as the main culprit of the current obesity epidemic [98]. Human studies have demonstrated changes in serum lipids and insulin sensitivity after short-term (6-day) feeding with fructose but only after consuming amounts $(25 \%$ of total daily energy) that are much higher than habitual intakes (less than $10 \%$ of energy) [99]. Great care should also be taken to identify other risk factors and to evaluate their relative roles within the complex network of metabolic interactions and hunger/satiety signaling. For example, even relatively short (6-7 day) dietary interventions with high fructose reveal gender-related differences, with more marked increases in serum triacylglycerol and hepatic insulin resistance in young males than in females [100], and in offspring from type 2 diabetic patients [101]. Furthermore, in diabetic patients dietary fructose uptake is more rapid due to (fructose-induced) up regulation and higher levels of GLUT 5 in the intestine [102]. In addition, intracellular fructose concentrations can rise substantially by endogenous conversion of glucose into fructose due to the increased flux along the polyol pathway that occurs during hyperglycemia [103, 104]. And finally, the above-mentioned lipogenesis, increased uric acid and advanced glycation products further compromise the already deficient endothelial function in diabetic patients $[98,105]$.

All these abnormalities seem difficult to reconcile with the fact that fructose itself has a low glycemic index and induces smaller increments in postprandial insulin in both diabetic and non-diabetic subjects [106]. Moreover, it is naturally extracted from fruits and vegetables that are indisputably healthy. Notwithstanding these considerations, it is obvious that processed foods and drinks with added (therefore, more bio-available) fructose differ in both quantity and quality from fruits containing intrinsic sugars. In order to analyze their metabolic impact correctly, more precise and sensitive markers of insulin resistance and dyslipidemia are required [88]. One would also need to report the percent of dietary energy supplied by fructose more accurately (using the recently proposed "fructose index") [107], and to specify the proportion of fructose derived from fruits/vegetables compared to that from sweets and drinks [108].

\section{DIETARY GUIDELINES FOR TOTAL CARBOHY- DRATES, GLYCEMIC INDEX, SUCROSE AND FRUCTOSE: NEED FOR REASSESSMENT?}

The 2003 joint WHO/FAO Expert consultation report, that advocated a balanced diet to prevent chronic diseases in general, recommended daily dietary intake ranges of $55-75 \%$ of total energy as carbohydrates [109]. The Institute of Medicine (IOM) and the American Diabetes Association (ADA) set these ranges at $45-65 \%$ with a minimum of 130 gram daily for adults, including diabetic patients [110,111]. It should be noted that these recommendations were derived not with the aim of preventing $\mathrm{CHO}$ deficiency but rather from the primary decision of setting upper limits of $35 \%$ energy for fats, based on the paradigm that high dietary fat predisposes to obesity and its complications. As illustrated in our discussion, these recommendations do not necessarily apply to all individuals and need reassessment.We propose that quantifying \% energy from $\mathrm{CHO}$ or fat is obsolete and misleading and that the interest should focus on the accurate characterization of the quality of each macronutrient and the means to prevent excessive caloric intake. 
As regards the glycemic index or load as a risk factor for obesity there is no consensus or guidelines, although some studies observed beneficial impacts by lowering GI by 4 units or glycemic load by 17 gram $[63,65]$. As mentioned in the section on glycemic index, accurate and reproducible quantification is difficult to achieve and strongly confounded by factors such as ripeness, food matrix, processing and inter-individual differences. Notwithstanding these constraints, in both type 1 and type 2 diabetic patients, diets with a low GI effectively result in a significant lowering of glycated hemoglobin thus demonstrating a clinically relevant improvement of glucose homeostasis [112]. Similar, and in some studies even better improvements are obtained after low CHO ketogenic diets [113], suggesting common beneficial effects in diabetes. Future, well-designed trials, testing food products with the same amounts of carbohydrate, fiber, protein and fat but with different GI need to be developed $[114,115]$.

With respect to "free" or "added" sugars (referring to all mono- and disaccharides naturally present in honey, syrups and fruit juices, plus those added to foods and soft drinks during manufacture and cooking) the upper limits set by the WHO and IOM were $<10 \%$ and $<25 \%$ energy respectively $[109,110]$. In 2002, the American Heart Association (AHA) did not find sufficient global evidence to label sugar as detrimental or beneficial. And hence it recommended that "high sugar intakes should be avoided" without specifying amounts [116]. The 2006 AHA Diet and Lifestyle Recommendations mentioned the need to limit beverages with added sugars or caloric sweeteners (namely sucrose, glucose, fructose, maltose, dextrose, corn syrups, concentrated fruit juice and honey) [117]. The most recent AHA recommendations are much more specific, setting as upper limits 100 and $150 \mathrm{kcal}$ of added sugars allowed daily for women and men respectively, stretching this limit up to $300 \mathrm{kcal}$ in the very physically active men. These allowances for added sugars (representing 3 to $9.6 \%$ of total energy needs) are notably lower than the above-mentioned $(10 \%)$ WHO guidelines [118]. Indeed, there is no consensus worldwide, as illustrated by the disparity between the various European countries in terms of recommendations (ranging from 8-15\% energy from sugars) and estimated intakes $[119,120]$.

When deciding on the daily maximum tolerated intakes of fructose it seems reasonable to examine the different target groups separately and to interpret the clinical relevance of the end-point being monitored. For example in healthy young males, intakes of around $50 \mathrm{~g} / \mathrm{d}$ (about the average intake in the United States) are associated with increased postprandial triacylglycerol and alterations in insulin sensitivity and intakes of $>100 \mathrm{~g} / \mathrm{d}$ with increased fasting triacylglycerol [100]. On the other hand, meta-analyses of intervention studies conclude that intakes up to $90 \mathrm{~g} / \mathrm{d}$ do not worsen blood glucose regulation and $\mathrm{HbA}_{1 \mathrm{c}}$. It should be noted, however, that these conclusions refer exclusively to studies not involving HFCS [121]. In spite of the lowering effect on blood glucose and $\mathrm{HbA}_{1 \mathrm{c}}$, also demonstrated in diabetic patients [106], the ADA does not promote the use of added fructose as sweetening agent, as opposed to fructose in fruits and vegetables [111]. This decision is based on the differences in intestinal absorption, metabolism and associated cardiovascular risk factors that are present in these patients (see the section on the metabolic effects of fructose).
In view of the evidence on sugars and fructose, an upper limit of $10 \%$ energy from "free or added sugars" seems arbitrary since these guidelines fail to distinguish between the various types of sugars, their source and method of food processing, their presence as solid or liquids and the relative composition of free unbound fructose and glucose.

\section{SUMMARY, CONCLUSIONS AND PERSPECTIVES}

In summary, experimental data at the cellular and tissue/organ level demonstrate that surplus calories in the form of various types of $\mathrm{CHO}$ cause pathological changes leading to insulin resistance, body fat deposition, dyslipemia and vascular dysfunction, as well as altered appetite control. However, the evidence from dietary intervention studies is still insufficient to establish a causal link, partly due to serious methodological limitations such as the definition and classification of the $\mathrm{CHO}$ and the lack of accurate biomarkers of the metabolic outcomes. In order to tackle these methodological difficulties, clear nomenclature and classification guidelines are urgently needed. We need a consensus on the meaning and pathophysiologic relevance of terms such as total, free, extrinsic/intrinsic, added/natural, simple/complex, of high or low glycemic or fructosemic index, cariogenic, milk sugars etc when referring to "sugars". For instance, we need to clearly distinguish between fructose contained in fruits and vegetables and fructose added to beverages or processed foods (currently about two-thirds of total fructose intake) [122]. The next step would be to set up acceptable ranges of intake for each pathophysiologically relevant component, with clear specifications for each group of individuals or disease and distinguishing between short- and longterm effects. And finally, to view dietary intakes in terms of habit and shift the emphasis from discrete nutrients to dietary patterns [123]. These guidelines can then be followed by public health experts, legislators and the food industry in order to ensure correct labeling and information to the consumer.

One possible approach to recognize the important interindividual variability in the metabolic response to the carbohydrates discussed in this review is to study the genetic susceptibility. Despite impressive advances in the investigation of the genetic background of obesity, the search for screening methods to identify the relevant genetic variants is complicated. This is mainly due to the multifactorial nature of obesity and the involvement of multiple genes scattered all over the genome. Only widespread multinational studies will be capable of unraveling their relevance and the underlying molecular interactions, not only between the genes themselves but with environmental factors such as diet and exercise [124]. Nevertheless, we expect in a foreseeable future, that each individual can adapt the general dietary recommendations according to his/her genetic profile and can thus benefit from personalized changes in the $\mathrm{CHO}$ content of their diet [125].

In any case, the guidelines that can be derived from the information summarized in this review are only relevant when considered within the context of the primary goal of achieving and maintaining a healthy body weight by balancing caloric intake and physical activity. 


\section{ACKNOWLEDGEMENTS, COMPETING INTERESTS AND AUTHORS CONTRIBUTIONS}

Both authors are funded by their respective universities and declare that they have no competing interests.

B.M.K. wrote the paper and has primary responsibility for the final content, L.P.G. provided the project conception and has primary responsibility for the final content. Both authors read and approved the final manuscript.

\section{REFERENCES}

[1] World Health Organization. Obesity: preventing and managing the global epidemic. Report No.: 98.1.1998. Geneva 1998.

[2] World Health Organization. WHO. Chronic diseases and health problems. Risk factor projections: overweight and obesity. Accessed on: 2008 Jul 24. Available at: http://www.who.int/chp/ chronic disease_report/part2_ch1/en/index $16 . \mathrm{html}$

[3] Willett WC, Dietz WH, Colditz GA. Guidelines for Healthy Weight. New Engl J Med 1999; 341: 427-34.

[4] Hill JO, Prentice AM. Sugar and body weight regulation. Am J Clin Nutr 1995; 62: 264S-73.

[5] Saris WH. Sugars, energy metabolism, and body weight control. Am J Clin Nutr 2003; 78: 850S-7.

[6] Hebebrand J, Sommerlad C, Geller F, Gorg T, Hinney A. The genetics of obesity: practical implications. Int J Obes Relat Metab Disord 2001; 25 (Suppl 1): S10-8.

[7] Corthesy-Theulaz I, den Dunnen JT, Ferre P, et al. Nutrigenomics: the impact of biomics technology on nutrition research. Ann Nutr Metab 2005; 49: 355-65.

[8] Rankinen T, Zuberi A, Chagnon YC, et al. The Human Obesity Gene Map: The 2005 Update. Obes Res 2006; 14: 529-644.

[9] Cummings JH, Stephen AM. Carbohydrate terminology and classification. Eur J Clin Nutr 2007; 61 (Suppl 1): S5-18.

[10] Owen OE, Reichard GA. Fuels consumed by man: interplay between carbohydrates and fatty acids. Progr Biochem Pharmacol 1971; 6: 177-213.

[11] Eaton SB. The ancestral human diet: what was it and should it be a paradigm for contemporary nutrition? Proc Nutr Soc 2006; 65: 1-6.

[12] Fairweather-Tait S. Human nutrition and food research: opportunities and challenges in the post-genomic era. Phil Trans R Soc B 2003; 358: 1709-27.

[13] Paton JHP. Relation of excessive carbohydrate ingestion to catarrhs and other diseases. Brit Med J 1933; 1: 738.

[14] Samaha FF, Iqbal N, Seshadri P, et al. A Low-Carbohydrate as Compared with a Low-Fat Diet in Severe Obesity. New Engl J Med 2003; 348: 2074-81.

[15] Foster GD, Wyatt HR, Hill JO, et al. A Randomized Trial of a Low-Carbohydrate Diet for Obesity. New Engl J Med 2003; 348: 2082-90.

[16] Volek JS, Phinney SD, Forsythe CE, et al. Carbohydrate restriction has a more favorable impact on the metabolic syndrome than a low fat diet. Lipids 2009; 44: 297-309.

[17] Ahrens RA. Sucrose, hypertension, and heart disease: an historical perspective. Am J Clin Nutr 1974; 27: 403-22.

[18] Volek JS, Sharman MJ, Forsythe CE. Modification of Lipoproteins by Very Low-Carbohydrate Diets. J Nutr 2005; 135: 1339-42.

[19] Antonis A, Bershon I. The influence of diet on serum triglycerides in South Africa white and Bantu prisoners. Lancet 1961; 1: 3-9.

[20] Acheson KJ, Schutz Y, Bessard T, Anantharaman K, Flatt JP, Jequier E. Glycogen storage capacity and de novo lipogenesis during massive carbohydrate overfeeding in man. Am J Clin Nutr 1988; 48: 240-7.

[21] McDevitt RM, Bott SJ, Harding M, Coward WA, Bluck LJ, Prentice AM. De novo lipogenesis during controlled overfeeding with sucrose or glucose in lean and obese women. Am J Clin Nutr 2001; 74: 737-46.

[22] Roberts R, Bickerton AS, Fielding BA, et al. Reduced oxidation of dietary fat after a short term high-carbohydrate diet. Am J Clin Nutr 2008; 87: 824-31.

[23] Hudgins LC, Hellerstein M, Seidman C, Neese R, Diakun J, Hirsch J. Human fatty acid synthesis is stimulated by a eucaloric low fat, high carbohydrate diet. J Clin Invest 1996; 97: 2081-91.
[24] Ishii S, IIzuka K, Miller BC, Uyeda K. Carbohydrate response element binding protein directly promotes lipogenic enzyme gene transcription. Proc Natl Acad Sci USA 2004; 101: 15597-602.

[25] Parks EJ. Effect of Dietary Carbohydrate on Triglyceride Metabolism in Humans. J Nutr 2001; 131: 2772S-4.

[26] Volek JS, Sharman MJ, Love DM, et al. Body composition and hormonal responses to a carbohydrate-restricted diet. Metabolism 2002; 51: 864-70.

[27] Due A, Larsen TM, Mu H, Hermansen K, Stender S, Astrup A Comparison of 3 ad libitum diets for weight-loss maintenance, risk of cardiovascular disease, and diabetes: a 6-mo randomized, controlled trial. Am J Clin Nutr 2008; 88: 1232-41.

[28] Claessens M, van Baak MA, Monsheimer S, Saris WH. The effect of a low-fat, high-protein or high-carbohydrate ad libitum diet on weight loss maintenance and metabolic risk factors. Int $\mathrm{J}$ Obes (Lond) 2009; 33: 296-304 .

[29] Bessesen DH, Bull S, Cornier MA. Trafficking of dietary fat and resistance to obesity. Physiol Behav 2008; 94: 681-8.

[30] Burke LM, Angus DJ, Cox GR, et al. Effect of fat adaptation and carbohydrate restoration on metabolism and performance during prolonged cycling. J Appl Physiol 2000; 89: 2413-21.

[31] Krieger JW, Sitren HS, Daniels MJ, Langkamp-Henken B. Effects of variation in protein and carbohydrate intake on body mass and composition during energy restriction: a meta-regression 1 . Am J Clin Nutr 2006; 83: 260-74.

[32] Cotton JR, Burley VJ, Weststrate JA, Blundell JE. Dietary fat and appetite: similarities and differences in the satiating effect of meals supplemented with either fat or carbohydrate. J Hum Nutr Diet 1994; 20: 186-99.

[33] Thorens B. Glucose sensing and the pathogenesis of obesity and type 2 diabetes. Int J Obes (Lond) 2008; 32 (Suppl 6): S62-71.

[34] Burley VJ. Commentary on Cotton, J. R., Burley, V. J., Westrate, J. A. \& Blundell, J. E. (1994) Dietary fat and appetite: similarities and differences in the satiating effect of meals supplemented with either fat or carbohydrate. J Hum Nutr Diet; 7, 11-24. J Hum Nutr Diet 2007; 20: 200-1.

[35] Thomas CD, Peters JC, Reed GW, Abumrad NN, Sun M, Hill JO. Nutrient balance and energy expenditure during ad libitum feeding of high-fat and high-carbohydrate diets in humans. Am J Clin Nutr 1992; 55: 934-42.

[36] Jiao H, Kaaman M, Dungner E, Kere J, Arner P, Dahlman I. Association analysis of positional obesity candidate genes based on integrated data from transcriptomics and linkage analysis. Int $\mathrm{J}$ Obes 2008; 32: 816-25.

[37] Martinez JA, Corbalan MS, Sanchez-Villegas A, Forga L, Marti A, Martinez-Gonzalez MA. Obesity risk is associated with carbohydrate intake in women carrying the Gln27Glu beta2adrenoceptor polymorphism. J Nutr 2003; 133: 2549-54.

[38] Marti A, Corbalan MS, Martinez-Gonzalez MA, Forga L, Martinez JA. CHO intake alters obesity risk associated with Pro12Ala polymorphism of PPARgamma gene. J Physiol Biochem 2002; 58: 219-20.

[39] Zhang Z, Gong RR, Du J, et al. Associations of the SREBP-1c gene polymorphism with gender-specific changes in serum lipids induced by a high-carbohydrate diet in healthy Chinese youth. Appl Physiol Nutr Metab 2011; 36: 226-32.

[40] Marino M, Masella R, Bulzomi P, Campesi I, Malorni W, Franconi F. Nutrition and human health from a sex-gender perspective. Mol Aspects Med 2011; 32: 1-70.

[41] Chong MF, Fielding BA, Frayn KN. Metabolic interaction of dietary sugars and plasma lipids with a focus on mechanisms and de novo lipogenesis. Proc Nutr Soc 2007; 66: 52-9.

[42] Jenkins DJ, Wolever TM, Taylor RH, et al. Glycemic index of foods: a physiological basis for carbohydrate exchange. Am J Clin Nutr 1981; 34: 362-6.

[43] Wolever TM, Jenkins DJ. The use of the glycemic index in predicting the blood glucose response to mixed meals. Am J Clin Nutr 1986; 43: 167-72

[44] Ludwig DS. The glycemic index: physiological mechanisms relating to obesity, diabetes, and cardiovascular disease. J Amer Med Assoc 2002; 287: 2414-23.

[45] Pi-Sunyer FX. Glycemic index and disease. Am J Clin Nutr 2002; 76: 290S-8.

[46] Foster-Powell K, Holt SH, Brand-Miller JC. International table of glycemic index and glycemic load values. Am J Clin Nutr 2002; 76: 5-56. 
[47] Wolever TM, Brand-Miller JC, Abernethy J, et al. Measuring the glycemic index of foods: interlaboratory study. Am J Clin Nutr 2008; 87: 247S-57.

[48] Howlett J, Ashwell M. Glycemic response and health: summary of a workshop. Am J Clin Nutr 2008; 87: 212S-6.

[49] Ludwig DS, Majzoub JA, Al Zahrani A, Dallal GE, Blanco I, Roberts SB. High glycemic index foods, overeating, and obesity. Pediatrics 1999; 103: e26.

[50] Kallio P, Kolehmainen M, Laaksonen DE, et al. Dietary carbohydrate modification induces alterations in gene expression in abdominal subcutaneous adipose tissue in persons with the metabolic syndrome: the FUNGENUT Study. Am J Clin Nutr 2007; 85: 1417-27.

[51] Salmeron J, Manson JE, Stampfer MJ, Colditz GA, Wing AL, Willett WC. Dietary fiber, glycemic load, and risk of non-insulindependent diabetes mellitus in women. J Amer Med Assoc 1997; 277: 472-7.

[52] Salmeron J, Ascherio A, Rimm EB, et al. Dietary fiber, glycemic load, and risk of NIDDM in men. Diabetes care 1997; 20: 545-50.

[53] Meyer KA, Kushi LH, Jacobs DR Jr., Slavin J, Sellers TA, Folsom AR. Carbohydrates, dietary fiber, and incident type 2 diabetes in older women. Am J Clin Nutr 2000; 71: 921-30.

[54] Hodge AM, English DR, O'Dea K, Giles GG. Glycemic index and dietary fiber and the risk of type 2 diabetes. Diabetes Care 2004; 27: 2701-6.

[55] Krishnan S, Rosenberg L, Singer M, et al. Glycemic index, glycemic load, and cereal fiber intake and risk of type 2 diabetes in US black women. Arch Int Med 2007; 167: 2304-9.

[56] Schulze MB, Liu S, Rimm EB, Manson JE, Willett WC, Hu FB. Glycemic index, glycemic load, and dietary fiber intake and incidence of type 2 diabetes in younger and middle-aged women. Am J Clin Nutr 2004; 80: 348-56.

[57] Sahyoun NR, Anderson AL, Tylavsky FA, et al. Dietary glycemic index and glycemic load and the risk of type 2 diabetes in older adults. Am J Clin Nutr 2008; 87: 126-31.

[58] Villegas R, Liu S, Gao YT, et al. Prospective study of dietary carbohydrates, glycemic index, glycemic load, and incidence of type 2 diabetes mellitus in middle-aged chinese women. Arch Int Med 2007; 167: 2310-6.

[59] Thomas DE, Elliott EJ, Baur L. Low glycaemic index or low glycaemic load diets for overweight and obesity. Cochrane Database Syst Rev 2007; (3): CD005105.

[60] Thomas D, Elliott EJ. Low glycaemic index, or low glycaemic load, diets for diabetes mellitus. Cochrane Database Syst Rev 2009; (1): CD006296.

[61] Barclay AW, Petocz P, Millan-Price J, et al. Glycemic index, glycemic load, and chronic disease risk--a meta-analysis of observational studies. Am J Clin Nutr 2008; 87: 627-37.

[62] de Munter JS, Hu FB, Spiegelman D, Franz M, van Dam RM. Whole grain, bran, and germ intake and risk of type 2 diabetes: a prospective cohort study and systematic review. PLoS Med 2007; 4: e261.

[63] Livesey G, Taylor R, Hulshof T, Howlett J. Glycemic response and health a systematic review and meta-analysis: relations between dietary glycemic properties and health outcomes. Am J Clin Nutr 2008; 87: 258S-68.

[64] Vrolix R, Mensink RP. Effects of glycemic load on metabolic risk markers in subjects at increased risk of developing metabolic syndrome. Am J Clin Nutr 2010; 92(2): 366-74

[65] Larsen TM, Dalskov SM, van Baak M, et al. Diets with High or Low Protein Content and Glycemic Index for Weight-Loss Maintenance. New Engl J Med 2010; 363: 2102-13.

[66] Yudkin J. Pure, white and deadly. London, New York: Penguin 1988.

[67] Grundy SM, Brewer HB Jr., Cleeman JI, Smith SC Jr., Lenfant C, for the Conference Participants. Definition of metabolic syndrome: report of the national heart, lung, and blood institute/american heart association conference on scientific issues related to definition. Circulation 2004; 109: 433-8.

[68] Bolton-Smith C, Woodward M. Dietary composition and fat to sugar ratios in relation to obesity. Int J Obes Relat Metab Disord 1994; 18: 820-8.

[69] Macdiarmid JI, Vail A, Cade JE, Blundell JE. The sugar-fat relationship revisited: differences in consumption between men and women of varying BMI. Int J Obes Relat Metab Disord 1998; 22: 1053-61.
[70] Gibney MJ. Dietary guidelines: a critical appraisal. J Hum Nutr Diet 1990; 3: 245-54.

[71] Ruxton CHS, Gardner EJ, McNulty HM. Is sugar consumption detrimental to health? A Review of the Evidence 1995-2006. Crit Rev Food Sci 2009; 50: 1-19.

[72] Saris WH, Astrup A, Prentice AM, et al. Randomized controlled trial of changes in dietary carbohydrate/fat ratio and simple vs complex carbohydrates on body weight and blood lipids: the CARMEN study. The Carbohydrate Ratio Management in European National diets. Int J Obes Relat Metab Disord 2000; 24: 1310-8.

[73] West JA, de Looy AE. Weight loss in overweight subjects following low-sucrose or sucrose-containing diets. Int J Obes Relat Metab Disord 2001; 25: 1122-8.

[74] Black RN, Spence M, McMahon RO, et al. Effect of eucaloric high- and low-sucrose diets with identical macronutrient profile on insulin resistance and vascular risk: a randomized controlled trial. Diabetes 2006; 55: 3566-72.

[75] Janket SJ, Manson JE, Sesso H, Buring JE, Liu S. A prospective study of sugar intake and risk of type 2 diabetes in women. Diabetes care 2003; 26: 1008-15.

[76] Abraira C, Derler J. Large variations of sucrose in constant carbohydrate diets in type II diabetes. Am J Med 1988; 84: 193200 .

[77] Kennedy ET, Bowman SA, Powell R. Dietary-fat intake in the US population. J Am Coll Nutr 1999; 18: 207-12.

[78] Gross LS, Li L, Ford ES, Liu S. Increased consumption of refined carbohydrates and the epidemic of type 2 diabetes in the United States: an ecologic assessment. Am J Clin Nutr 2004; 79: 774-9.

[79] Malik VS, Popkin BM, Bray GA, Despros JP, Willett WC, Hu FB Sugar sweetened beverages and risk of metabolic syndrome and type 2 diabetes: a meta-analysis. Diabetes Care 2010; 33(11): 2477 83

[80] Welsh JA, Sharma A, Abramson JL, Vaccarino V, Gillespie C, Vos MB. Caloric sweetener consumption and dyslipidemia among US adults. J Amer Med Assoc 2010; 303: 1490-7.

[81] van Dam RM, Seidell JC. Carbohydrate intake and obesity. Eur J Clin Nutr 2007; 61: S75-99.

[82] Schulze MB, Manson JE, Ludwig DS, et al. Sugar-Sweetened Beverages, Weight Gain, and Incidence of Type 2 Diabetes in Young and Middle-Aged Women. J Amer Med Assoc 2004; 292: 927-34.

[83] Ludwig DS, Peterson KE, Gortmaker SL. Relation between consumption of sugar-sweetened drinks and childhood obesity: a prospective, observational analysis. The Lancet 2001; 357: 505-8

[84] Marriott BP, Cole N, Lee E. National estimates of dietary fructose intake increased from 1977 to 2004 in the United States. J Nutr 2009; 139: 1228S-35.

[85] Miyazaki M, Dobrzyn A, Man WC, et al. Stearoyl-CoA Desaturase 1 Gene Expression Is Necessary for Fructose-mediated Induction of Lipogenic Gene Expression by Sterol Regulatory Element-binding Protein-1c-dependent and -independent Mechanisms. J Biol Chem 2004; 279: 25164-71.

[86] Stanhope KL, Havel PJ. Fructose consumption: potential mechanisms for its effects to increase visceral adiposity and induce dyslipidemia and insulin resistance. Curr Opin Lipidol 2008; 19: 16-24.

[87] Chong MF, Fielding BA, Frayn KN. Mechanisms for the acute effect of fructose on postprandial lipemia. Am J Clin Nutr 2007; 85: $1511-20$

[88] Aeberli I, Zimmermann MB, Molinari L, et al. Fructose intake is a predictor of LDL particle size in overweight schoolchildren. Am J Clin Nutr 2007; 86: 1174-8.

[89] Bantle JP, Raatz SK, Thomas W, Georgopoulos A. Effects of dietary fructose on plasma lipids in healthy subjects. The Am J Clin Nutr 2000; 72: 1128-34.

[90] Swarbrick MM, Stanhope KL, Elliott SS, et al. Consumption of fructose-sweetened beverages for 10 weeks increases postprandial triacylglycerol and apolipoprotein-B concentrations in overweight and obese women. Br J Nutr 2008; 100(5): 947-52.

[91] Le KA, Faeh D, Stettler R, et al. Effects of four-week high-fructose diet on gene expression in skeletal muscle of healthy men. Diabetes Metab 2008; 34: 82-5.

[92] Stanhope KL, Schwarz JM, Keim NL, et al. Consuming fructosesweetened, not glucose-sweetened, beverages increases visceral 
adiposity and lipids and decreases insulin sensitivity in overweight/obese humans. J Clin Invest 2009; 119: 1322-34.

[93] Teff KL, Elliott SS, Tschop M, et al. Dietary fructose reduces circulating insulin and leptin, attenuates postprandial suppression of ghrelin, and increases triglycerides in women. J Clin Endocrinol Metab 2004; 89: 2963-72.

[94] Nakagawa T, Hu H, Zharikov S, et al. A causal role for uric acid in fructose-induced metabolic syndrome. Am J Physiol Renal Physiol 2006; 290: F625-31

[95] Tran LT, Yuen VG, McNeill JH. The fructose-fed rat: a review on the mechanisms of fructose-induced insulin resistance and hypertension. Mol Cell Biochem 2009; 332(1-2): 145-59.

[96] Elliott SS, Keim NL, Stern JS, Teff K, Havel PJ. Fructose, weight gain, and the insulin resistance syndrome. Am J Clin Nutr 2002; 76: $911-22$.

[97] Vlassara H, Striker G. Glycotoxins in the diet promote diabetes and diabetic complications. Curr Diab Rep 2007; 7: 235-41.

[98] Johnson RJ, Perez-Pozo SE, Sautin YY, et al. Hypothesis: could excessive fructose intake and uric acid cause type 2 diabetes? Endocr Rev 2009; 30: 96-116.

[99] Faeh D, Minehira K, Schwarz JM, Periasamy R, Park S, Tappy L. Effect of fructose overfeeding and fish oil administration on hepatic de novo lipogenesis and insulin sensitivity in healthy men. Diabetes 2005; 54: 1907-13.

[100] Couchepin C, Le KA, Bortolotti M, et al. Markedly blunted metabolic effects of fructose in healthy young female subjects compared with male subjects. Diabetes care 2008; 31: 1254-6.

[101] Le KA, Ith M, Kreis R, et al. Fructose overconsumption causes dyslipidemia and ectopic lipid deposition in healthy subjects with and without a family history of type 2 diabetes. Am J Clin Nutr 2009; 89: 1760-5

[102] Dyer J, Wood IS, Palejwala A, Ellis A, Shirazi-Beechey SP. Expression of monosaccharide transporters in intestine of diabetic humans. Am J Physiol Gastrointest Liver Physiol 2002; 282: G2418 .

[103] Williamson J, Chang K, Frangos M, Hasan K, Tilton R. Hyperglycemic pseudohypoxia and diabetic complications. Diabetes 1993; 42: 801-13.

[104] Brownlee M. The Pathobiology of Diabetic Complications: A Unifying Mechanism. Diabetes 2005; 54: 1615-25.

[105] Johnson RJ, Segal MS, Sautin Y, et al. Potential role of sugar (fructose) in the epidemic of hypertension, obesity and the metabolic syndrome, diabetes, kidney disease, and cardiovascular disease. Am J Clin Nutr 2007; 86: 899-906.

[106] Bantle JP. Dietary fructose and metabolic syndrome and diabetes. J Nutr 2009; 139: 1263S-8.

[107] Segal M, Gollub E, Johnson R. Is the fructose index more relevant with regards to cardiovascular disease than the glycemic index? Eur J Nutr 2007; 46: 406-17.

[108] Sharma S, Roberts L, Lustig R, Fleming S. Carbohydrate intake and cardiometabolic risk factors in high BMI African American children. Nutr Metab 2010; 7: 10.
[109] WHO. Diet, Nutrition and the Prevention of Chronic Diseases: Report of a Joint WHO/FAO Expert Consultation. Report No.: 916. Geneva, Swtizerland: World Health Organization 2003.

[110] Institute of Medicine FaNB. Dietary Reference Intakes: Energy, Carbohydrates, Fiber, Fat, Fatty Acids, Cholesterol, Protein, and Amino Acids. Washington DC: National Academic Press 2002.

[111] American Diabetes Association. Nutrition recommendations and interventions for diabetes-2006: A position statement of the American Diabetes Association. Diabetes Care 2006; 29: 2140-57.

[112] Brand-Miller J, Hayne S, Petocz P, Colagiuri S. Low-glycemic index diets in the management of diabetes: a meta-analysis of randomized controlled trials. Diabetes care 2003; 26: 2261-7.

[113] Westman E, Yancy W, Mavropoulos J, Marquart M, McDuffie J. The effect of a low-carbohydrate, ketogenic diet versus a lowglycemic index diet on glycemic control in type 2 diabetes mellitus. Nutr Metab 2008; 5: 36.

[114] Ludwig DS. Clinical update: the low-glycaemic-index diet. Lancet 2007; 369(9565): 890-2.

[115] Vrolix R, van Meijl LE, Mensink RP. The metabolic syndrome in relation with the glycemic index and the glycemic load. Physiol Behav 2008; 94: 293-9.

[116] Howard BV, Wylie-Rosett J. Sugar and cardiovascular disease: a statement for healthcare professionals from the committee on nutrition of the council on nutrition, physical activity, and metabolism of the american heart association. Circulation 2002; 106: 523-7.

[117] Lichtenstein AH, Appel LJ, Brands M, et al. Diet and lifestyle recommendations revision 2006: a scientific statement from the american heart association nutrition committee. Circulation 2006 114: 82-96.

[118] Johnson RK, Appel LJ, Brands M, et al. Dietary sugars intake and cardiovascular health: a scientific statement from the american heart association. Circulation 2009; 120: 1011-20.

[119] Ruxton CH, Garceau FJ, Cottrell RC. Guidelines for sugar consumption in Europe: is a quantitative approach justified? Eur J Clin Nutr 1999; 53: 503-13.

[120] Schmidhuber J, Traill WB. The changing structure of diets in the European Union in relation to healthy eating guidelines. Public Health Nutr 2006; 9: 584-95.

[121] Livesey G, Taylor R. Fructose consumption and consequences for glycation, plasma triacylglycerol, and body weight: meta-analyses and meta-regression models of intervention studies. Am J Clin Nutr 2008; 88: 1419-37.

[122] Duffey KJ, Popkin BM. High-fructose corn syrup: is this what's for dinner? Am J Clin Nutr 2008; 88: 1722S-32.

[123] Mozaffarian D, Ludwig DS. Dietary Guidelines in the $21 \mathrm{st}$ Century--a Time for Food. J Amer Med Assoc 2010; 304: 681-2.

[124] Korner A, Kiess W, Stumvoll M, Kovacs P. Polygenic contribution to obesity: genome-wide strategies reveal new targets. Front Horm Res 2008; 36: 12-36.

[125] Arkadianos I, Valdes A, Marinos E, Florou A, Gill R, Grimaldi K. Improved weight management using genetic information to personalize a calorie controlled diet. Nutr J 2007; 6: 29. 